KINETIK, Vol. 2, No. 1, Februari 2017, Hal. 43-52

ISSN : 2503-2259,

E-ISSN : 2503-2267

\title{
Desain Interaksi Pada Gamifikasi Dalam Pemesanan Taksi Online
}

\author{
Supriyanto ${ }^{* 1}$, Ary Setijadi Prihatmanto ${ }^{2}$ \\ ${ }^{1}$ Universitas Ahmad Dahlan, ${ }^{2}$ STEl Institut Teknologi Bandung/ ITB Research Center on ICT \\ supriyanto@tif.uad.ac.id
}

\begin{abstract}
Abstrak
Aplikasi pemesanan taksi online saat ini menjadi salah satu bagian penting dalam transportasi umum khususnya taksi. Tujuan dari aplikasi ini adalah mempermudah pemesanan taksi yang dilakukan oleh masyarakat. Kemudahan penggunaan transportasi umum diharapkan dapat mengurangi penggunaan kendaraan pribadi. Sehingga akan dapat mengurangi kemacetan lalu lintas di daerah perkotaan. Tetapi mempermudah saja tidak cukup, perlu suatu pendekatan lain agar masyarakat selalu menggunakan aplikasi pemesanan tersebut setiap saat melakukan perjalanan. Salah satu aplikasi hasil penelitian dengan topik Intelligent Transportation System yaitu Semut Aplikasi memasukkan pendekatan gamifikasi dalam fitur pemesanan taksi online. Desain interaksi yang digunakan dalam gamifikasi pada pemesanan taksi online bertujuan untuk memudahkan pengguna dapat berinteraksi dengan aplikasi dengan baik dalam kehidupan sehari-hari. Artikel ini mendeskripsikan tentang bagaimana bentuk desain interaksi gamifikasi pada pemesanan taksi online yang sesuai dengan kebutuhan dan dapat diterima dengan baik oleh pengguna.
\end{abstract}

Kata kunci: Desain interaksi, Activity-centered design, Gamifikasi, Intelligent transport system, Framework D6

\begin{abstract}
Online booking application is nowadays taking significant role in public transportation, especially taxi. This application aims to facilitate its users to book taxi in a very easy way. Thus, it is expected that by the ease of public transportation access would lead to reduce the use of private vehicles. Therefore, it could reduce the traffic congestion in urban area. However, just facilitating is not enough, another approach needed to make its users always use the application every time they want to do a travel. This research resulted an application of Intelligent Transportation System named Semut App by including gamification into online booking features. Interactive design used in online booking gamificasion could help its users to have well interaction in everyday life. This paper describes how to design interactive gamification for online booking application in order to make it in line with people's need and be well accepted.
\end{abstract}

Keywords: Interaction design, Activity-centered design, Gamification, Intelligent transport system, D6 framework

\section{Pendahuluan}

Kemacetan lalu lintas biasanya banyak terjadi pada daerah perkotaan dan menjadi masalah utama transportasi. Masyarakat perkotaan biasanya memiliki kendaraan pribadi untuk mendukung mobilitas yang tinggi. Kendaraan pribadi dianggap lebih aman dan lebih fleksibel untuk mendukung aktivitas sehari-hari. Taksi adalah salah satu sarana transportasi umum yang memiliki beberapa kelebihan, yakni memiliki jam operasi tak terbatas, jalur yang tidak terbatas, dan memberikan kesan eksklusif kepada penggunanya. Taksi juga memiliki pengemudi profesional dibandingkan dengan pengemudi kendaraan pribadi [1]. Hal ini berpengaruh pada kedisiplinan dan ketertiban saat berkendara. Berdasarkan kelebihan yang ditawarkan tersebut, taksi dapat menjadi salah satu solusi untuk mengurangi kemacetan lalu lintas.

Berbagai usaha dilakukan untuk meningkatkan layanan taksi, salah satunya adalah dengan munculnya konsep pemesanan taksi online. Masyarakat dapat memesan taksi dengan 
cepat dan mudah dengan berbagai aplikasi pemesanan taksi online. Akan tetapi, pemesanan taksi memiliki beberapa tantangan, salah satunya adalah masalah keamanan data pengguna perlu diperhatikan lebih. Berbagai jenis aplikasi pemesanan taksi online mulai bermunculan. Hal ini justru membingungkan masyarakat sebagai penggunanya. User harus memasang aplikasi yang berbeda apabila ingin menggunakan taksi yang berbeda perusahaan. Sehingga banyak pengguna justru merasa kesulitan untuk memesan taksi menggunakan aplikasi pemesanan online, karena banyaknya aplikasi yang harus dipasang dan dioperasikan dalam gawainya.

Berdasarkan masalah yang ditimbulkan dari keanekaragaman aplikasi pemesanan taksi online yang ada, maka diperlukan suatu integrasi yang tepat, agar pengguna cukup memasang satu saja aplikasi yang dapat menjangkau semua perusahaan taksi. Sehingga pengguna lebih mudah dalam mengoperasikannya dan benar-benar merasakan kemudahan memesan taksi menggunakan aplikasi pemesanan online. Semut App adalah salah satu produk hasil penelitian intelligent transportation sistem yang menggunakan Bandung sebagai objek penelitian [2]. Semut App awalnya adalah aplikasi sosial media berbasis lokasi yang dapat digunakan sebagai navigasi, social network, dan traffic monitoring. Selanjutnya, Semut App memiliki fitur baru yang digunakan untuk melayani masalah transportasi umum salah satunya adalah layanan pemesanan taksi.

Layanan pemesanan taksi yang ada di dalam Semut App terintegrasi dengan konsep social media. Selain itu, pada layanan pemesanan taksi juga diterapkan gamifikasi baik dari sisi penumpang maupun pengemudi taksi. Gamifikasi adalah penerapan elemen game sistem yang tidak berbasis game [3]. Gamifikasi bertujuan untuk meningkatkan motivasi pengguna agar selalu menggunakan layanan taksi tersebut untuk memesan taksi. Gamifikasi juga berdampak pada pengemudi taksi agar termotivasi untuk meningkatkan layanan taksi yang diberikan, sehingga penumpang merasa aman, nyaman, dan puas ketika menggunakan taksi sebagai alat transportasi selalu beraktivitas sehari-hari.

Gamifikasi diharapkan dapat meningkatkan partisipasi dan keterlibatan user dalam setiap proses yang ada di dalam aplikasi. Sebaliknya, penerapan gamifikasi diharapkan dapat membuat aplikasi menjadi bagian penting dalam kehidupan sehari-hari pengguna. Maka dari itu, diperlukan desain interaksi yang dapat mengakomodasi interaksi pengguna dengan aplikasi pemesanan taksi.

\section{Metode Penelitian}

Desain interaksi Semut App menggunakan pendekatan activity-centered design. Pedekatan activity-centered design menjadikan aktivitas utama pengguna sistem sebagai bentuk desain interaksi [4]. Garis besar metodologi penelitian yang digunakan terlihat pada Gambar 1.

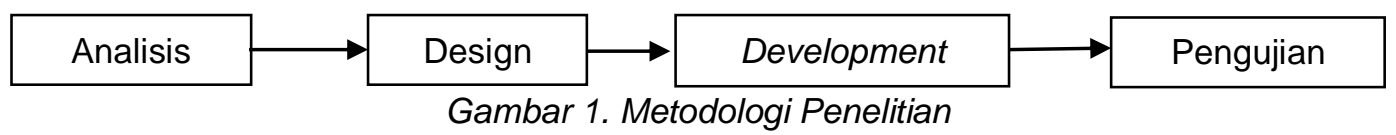

Metode penelitian pembuatan desain interaksi gamifikasi dalam pemesanan taksi online diawali dengan melakukan analisis menggunakan gamification design framework (D6) [5]. Framework D6 merupakan salah satu framework untuk merancang bentuk gamifikasi. Framework digunakan dalam pembuatan desain interaksi karena D6 dapat menunjukkan kebutuhan sistem dan aktivitas yang dilakukan pengguna sistem dalam konsep gamifikasi.

Langkah-langkah dalam Framework D6 adalah sebagai berikut:

1. Define business objectives, yaitu menentukan tujuan gamifikasi pada aplikasi/sistem pemesanan taksi online.

2. Delineate target behaviors, yaitu merumuskan target perilaku/kondisi yang diharapkan dari penerapan gamifikasi aplikasi/sistem pemesanan taksi online.

3. Describe players, yaitu menentukan siapa saja yang menjadi pemain di dalam gamifikasi aplikasi/sistem pemesanan taksi online.

4. Devise activity loops, yaitu menentukan aktivitas pemain di dalam gamifikasi aplikasi/sistem pemesanan taksi online.

5. Don't forget the fun, yaitu menambahkan aktivitas yang mengandung unsur menyenangkan sebagai salah satu ciri game. 
6. Deploy with appropriate tools, yaitu implementasi konsep gamifikasi menggunakan alat yang tepat.

Target tujuan dari aplikasi atau sistem pemesanan taksi online adalah memudahkan masyarakat melakukan pemesanan taksi, sehingga dapat menunjang aktivitas sehari-hari yang memerlukan mobilitas tinggi. Kemudahan tersebut diharapkan dapat berdampak pada motivasi dan loyalitas masyarakat untuk menggunakan transportasi umum untuk dapat mengurangi kemacetan.

Pembuatan desain interaksi gamifikasi hanya menggunakan sebagian tahapan dalam Framework D6. Langkah D6 yang digunakan adalah menggambarkan perilaku target/pengguna, mendeskripsikan pemain, merancang siklus aktivitas, aspek "kesenangan". Hasil dari sebagian langkah Framework D6 itulah yang akan menjadi landasan bentuk desain interaksi gamifikasi dalam aplikasi pemesanan taksi online.

\section{Hasil Penelitian dan Pembahasan}

Berikut adalah hasil analisis kebutuhan interaksi, berdasarkan perumusan tujuan aplikasi/sistem pemesanan taksi online hasil dari analisis langkah pertama D6 Framework.

\subsection{Delineate Target Behaviors}

berikut:

Target perilaku pengguna aplikasi atau system pemesanan taksi online adalah sebagai

1. Aplikasi selalu terpasang pada gawai pengguna.

2. Pengguna selalu mencari dan memesan taksi menggunakan aplikasi setiap akan melakukan perjalanan.

3. Pengguna memberikan feedback dan penilaian terhadap taksi.

4. Pengemudi taksi memberikan pelayanan terhadap penumpang yang memesan menggunakan aplikasi untuk menjaga reputasi taksinya.

\subsection{Describe Players}

Terdapat dua pemain yang menjadi aktor dalam gamifikasi system pemesanan taksi online. Pemain pertama adalah masyarakat sebagai calon penumpang dan penumpang taksi. Pemain kedua adalah pengemudi taksi yang nantinya akan merespons pesanan taksi dari calon penumpang. Pengemudi taksi yang bisa mendaftar adalah kendaraannya memiliki nomor lambung sesuai dengan ketentuan perusahaan masing-masing. Penumpang akan berkompetisi dengan sesama penumpang, sedangkan pengemudi juga akan berkompetisi dengan sesama pengemudi taksi lainnya.

\subsection{Devise Activity Loops}

Siklus aktivitas pengguna ditentukan menjadi 3 bagian, yaitu aktivitas pengguna, mengapa pengguna harus melakukannya, dan reaksi/respons dari aplikasi untuk menanggapi aktivitas pengguna. Tabel 1 menunjukkan siklus aktivitas pemain pertama/penumpang, sedangkan Tabel 2 menunjukkan siklus aktivitas pemain kedua/pengemudi taksi.

\subsection{Don't Forget The Fun}

Unsur menyenangkan yang ditambahkan dalam system adalah penggunaan komponen game, reward, dan reputasi. Reward diwujudkan dalam bentuk poin yang dikumpulkan penumpang ketika memesan dan memberikan penilaian. Sedangkan pengemudi, mendapatkan poin berdasarkan keaktifannya menerima pesanan. Reputasi diwujudnya dalam penggunaan badges/lencana. Badges yang digunakan untuk menunjukkan level pengguna berdasarkan etika dan loyalitas dalam menggunakan aplikasi. Badges diberikan kepada kedua pemain, dengan masing-masing kriteria kenaikan level yang berbeda. Penerapan komponen game ini dapat memotivasi dan mengajak para pemain untuk berlomba menjadi yang terbaik.

Selain penggunaan komponen game, system pemesanan taksi juga diintegrasikan dengan aplikasi jejaring social berbasis lokasi, yaitu Semut App. Penggunaan avatar, konsep pertemanan, dan konsep berbagi terintegrasi dengan poin dan badges yang didapatkan penumpang. 
Tabel 1. Siklus Aktivitas Penumpang

\begin{tabular}{|c|c|c|}
\hline Aktivitas penumpang & Alasan/tujuan & Respons aplikasi \\
\hline $\begin{array}{l}\text { Memesan taksi dalam } \\
\text { keadaan login. }\end{array}$ & $\begin{array}{l}\text { Data penumpang diperlukan } \\
\text { untuk pendataan pemesanan } \\
\text { dan memastikan penumpang } \\
\text { yang memesan taksi bukan } \\
\text { robot dan bukan spam. }\end{array}$ & $\begin{array}{l}\text { Apabila belum login, maka } \\
\text { aplikasi menampilkan } \\
\text { peringatan agar pengguna } \\
\text { login ke dalam system terlebih } \\
\text { dahulu. }\end{array}$ \\
\hline $\begin{array}{l}\text { Calon menumpang } \\
\text { menunggu proses } \\
\text { pencarian. }\end{array}$ & $\begin{array}{l}\text { Aplikasi memerlukan waktu } \\
\text { untuk menemukan taksi-taksi } \\
\text { terdekat dan pengemudi } \\
\text { harus menerima pesanan } \\
\text { terlebih dahulu. }\end{array}$ & $\begin{array}{l}\text { Sistem memberikan informasi } \\
\text { waktu yang diperlukan untuk } \\
\text { mencari. }\end{array}$ \\
\hline $\begin{array}{l}\text { Membatalkan proses } \\
\text { pencarian atau } \\
\text { membatalkan pesanan } \\
\text { yang sudah diterima } \\
\text { pengemudi taksi }\end{array}$ & $\begin{array}{l}\text { Pencarian terlalu lama atau } \\
\text { penumpang tidak mau } \\
\text { menggunakan taksi tersebut } \\
\text { karena memiliki reputasi yang } \\
\text { kurang bagus. }\end{array}$ & $\begin{array}{l}\text { Sistem memberikan reputasi } \\
\text { negatif bagi calon penumpang } \\
\text { yang membatalkan pesanan. } \\
\text { Pembatalan proses pencarian } \\
\text { tidak mendapatkan reputasi } \\
\text { negatif. }\end{array}$ \\
\hline $\begin{array}{l}\text { Memberikan penilaian } \\
\text { kepada pengemudi taksi } \\
\text { dan penilaian untuk fasilitas } \\
\text { taksi yang ada. }\end{array}$ & $\begin{array}{l}\text { Pengemudi dan fasilitas taksi } \\
\text { perlu mendapatkan penilaian } \\
\text { untuk menunjukkan memiliki } \\
\text { reputasi yang baik atau tidak }\end{array}$ & $\begin{array}{l}\text { Reputasi positif kepada } \\
\text { penumpang yang } \\
\text { memberikan penilaian. }\end{array}$ \\
\hline
\end{tabular}

Tabel 2. Siklus Aktivitas Pengemudi Taksi

\begin{tabular}{lll}
\hline \multicolumn{1}{c}{ Aktivitas pengemudi } & \multicolumn{1}{c}{ Alasan/tujuan } & \multicolumn{1}{c}{ Respons aplikasi } \\
\hline $\begin{array}{l}\text { Memastikan aplikasi } \\
\text { dalam keadaan standby } \\
\text { dan kondisi logged in }\end{array}$ & $\begin{array}{l}\text { Memudahkan pencarian taksi } \\
\text { oleh calon penumpang. }\end{array}$ & $\begin{array}{l}\text { Tambahan poin untuk 24 jam } \\
\text { mengaktifkan aplikasi. }\end{array}$ \\
\hline $\begin{array}{l}\text { Memastikan identitas yang } \\
\text { terpasang pada aplikasi } \\
\text { benar dan lengkap }\end{array}$ & $\begin{array}{l}\text { Memastikan tidak ada taksi } \\
\text { palsu, dan memudahkan calon } \\
\text { penumpang untuk } \\
\text { mengidentifikasi identitas taksi }\end{array}$ & $\begin{array}{l}\text { Menambahkan 100 poin } \\
\text { kepada pengemudi }\end{array}$ \\
\hline $\begin{array}{l}\text { Sesegera mungkin } \\
\text { menerima pesanan taksi } \\
\text { yang masuk dari aplikasi }\end{array}$ & $\begin{array}{l}\text { Agar menjadi taksi tercepat } \\
\text { dan mendapatkan penumpang }\end{array}$ & $\begin{array}{l}\text { Menambahkan 5 poin jika } \\
\text { pada akhirnya terjadi } \\
\text { transaksi. }\end{array}$ \\
\hline
\end{tabular}

\subsection{Perancangan Interaksi dan Antarmuka}

Berdasarkan hasil analisis menggunakan Framework D6 maka dapat dirumuskan desain interaksi sebagai berikut.

\subsubsection{Aktivitas Pemesanan Taksi dan Login}

Rancangan interaksi pada aktivitas pemesanan taksi dan login oleh calon penumpang dibuat dalam 4 antarmuka, yaitu:

1. Antarmuka utama pemesanan

Berisi tombol untuk memulai pemesanan taksi. Antarmuka ini dilengkapi dengan kalimat dan kata-kata sebagai petunjuk.

2. Antarmuka peringatan login

Ketika pengguna mulai pemesanan dan tidak dalam keadaan login, maka tampil antarmuka yang mengarahkan pengguna masuk ke antarmuka login/registrasi.

3. Antarmuka pilihan untuk menentukan lokasi tujuan perjalanan atau tidak.

Apabila dalam keadaan login, maka akan tampil antarmuka pilihan apakah pengguna akan menentukan lokasi tujuan perjalanan atau tidak. Jika tidak, maka tampil antarmuka pencarian.

4. Antarmuka menentukan lokasi tujuan

Apabila pengguna memilih menentukan lokasi tujuan, maka tampil antarmuka menentukan lokasi tujuan. 


\subsubsection{Aktivitas Proses Pencarian Taksi}

Rancangan interaksi pada aktivitas pencarian taksi dibagi menjadi dua antarmuka, yaitu:

1. Antarmuka proses pencarian

Proses pencarian taksi dengan cara mengirimkan broadcast permintaan pemesanan kepada taksi-taksi yang lokasinya terdekat dengan pengguna. Kemudian harus menunggu ada taksi yang menerima permintaan pesanan. Antarmuka proses pencarian tersebut menampilkan countdown timer. Ketika waktu habis, maka tampil antarmuka pilihan untuk mengulang pencarian atau membatalkan pesanan.

2. Antarmuka pesanan diterima oleh pengemudi taksi

Ketika ada pengemudi taksi yang menerima permintaan pesanan, maka tampil antarmuka yang berisi informasi tentang taksi yang menerima permintaan pesanan. Antarmuka ini memberikan pilihan kepada pengguna apakah menyetujui atau membatalkan pesanan. Pengemudi akan mendapatkan tampilkan menunggu konfirmasi dari pengguna/calon penumpang di waktu yang sama.

\subsubsection{Aktivitas Menilai Taksi}

Rancangan interaksi pada aktivitas menilai taksi dan pengemudinya dibuat dalam 2 antarmuka, yaitu:

1. Antarmuka detail pesanan

Penumpang mendapatkan tampilan detail pesanan yang terdiri dari peta untuk informasi dan visualisasi rute perjalanan, informasi taksi beserta bio pengemudi, dan informasi estimasi jarak tempuh dan biaya perjalanan.

2. Antarmuka menilai taksi dan pengemudi

Antarmuka ini akan muncul ketika penumpang menekan tombol Rate Driver untuk menilai pengemudi dan Rate Car untuk menilai taksi. Baik Rate Driver dan Rate Car memiliki tampilan yang sama, yaitu skor diberikan dengan nilai 0 sampai dengan 5 . Skor 0 untuk sangat tidak bagus dan skor 5 untuk sangat bagus.

\subsubsection{Aktivitas Isi Identitas Pengemudi}

Rancangan interaksi pada aktivitas pengemudi taksi mengisi identitas dibuat dalam 3 antarmuka, yaitu:

1. Antarmuka login

Pengemudi harus login ke dalam system ketika akan menggunakan Semut Taxi. Mekanisme login pengemudi cukup menggunakan nomor telepon yang aktif. Sehingga antarmuka login hanya terdiri dari satu form isian untuk memasukkan nomor telepon.

2. Antarmuka verifikasi

Selanjutnya tampil antarmuka verifikasi nomor telepon dengan memasukkan code verifikasi yang dikirim system melalui pesan singkat ke nomor yang digunakan untuk login.

3. Antarmuka isian identitas diri dan taksi

Pengemudi diarahkan langsung ke antarmuka isian identitas diri dan taksi. Pengemudi juga diminta untuk memasang foto yang jelas sehingga pengemudi akan mudah dikenali selain menggunakan nama ataupun nomor taksi.

\subsubsection{Aktivitas Standby Aplikasi Semut Taxi}

Rancangan interaksi aktivitas standby aplikasi Semut Taxi dibuat dalam satu antarmuka, berisi informasi daftar pesanan yang masuk. Ketika ada pesanan baru yang masuk, maka pesanan tersebut akan berada di posisi teratas. Tersedia pula tombol untuk refresh daftar pesanan yang masuk.

\subsubsection{Aktivitas menerima pesanan}

Rancangan interaksi aktivitas menerima pesanan dibuat dalam dua antarmuka, yaitu:

1. Antarmuka detail permintaan pesanan

Pengemudi menerima pesanan dengan cara memilih salah satu pesanan yang masuk pada daftar pesanan. Selanjutnya tampil antarmuka detail permintaan pesanan berisi informasi data calon penumpang, peta lokasi calon penumpang dan tujuan. 
2. Antarmuka menunggu konfirmasi penumpang

Apabila pengemudi menekan tombol take order, maka tampil antarmuka menunggu konfirmasi penumpang untuk menyetujui transaksi. Ketika antarmuka ini tampil pada aplikasi pengemudi, aplikasi penumpang menampilkan detail taksi yang bersangkutan.

\subsection{Development Desain Interaksi}

Berdasarkan hasil perancangan interaksi dari aktivitas yang ada di aplikasi Semut App untuk penumpang dan Semut Taxi untuk pengemudi taksi telah dibangun antarmuka, seperti ditunjukkan oleh Gambar 1, Gambar2, Gambar 3, Gambar 4, Gambar 5, Gambar 6, Gambar 7, Gambar 8, dan Gambar 9. Interface tersebut dibangun menggunakan Google material design dengan bantuan IDE Android Studio.

1. Antarmuka aktivitas pemesanan taksi dan login

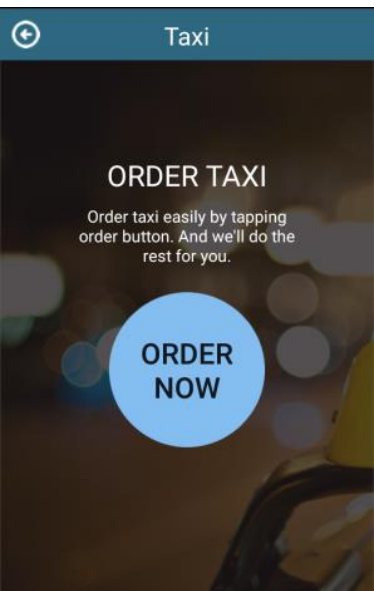

a

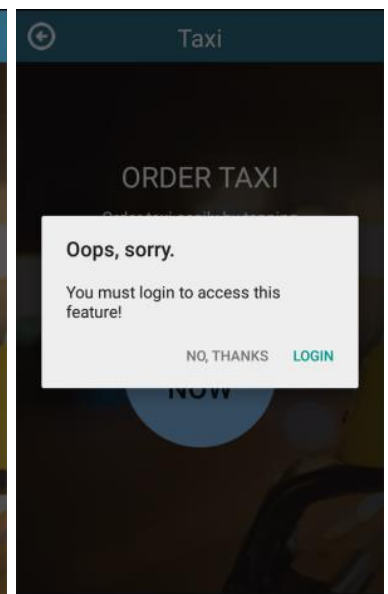

b

Gambar 2 (a) (b). Tampilan Utama Fitur Pemesanan Taksi dan Tampilan Peringatan Login

Antarmuka utama pemesanan taksi Gambar 2 (a) hanya berisi tombol utama berbentuk lingkaran warna biru dengan teks "ORDER NOW". Gambar 2 (b) menunjukkan peringatan untuk melakukan login. Login berfungsi untuk merekam data penumpang sehingga poin dan reputasi penumpang dapat diolah oleh system.

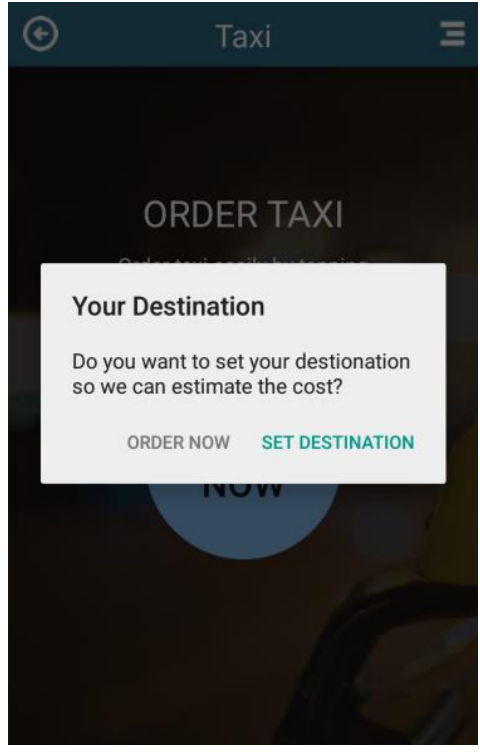

a

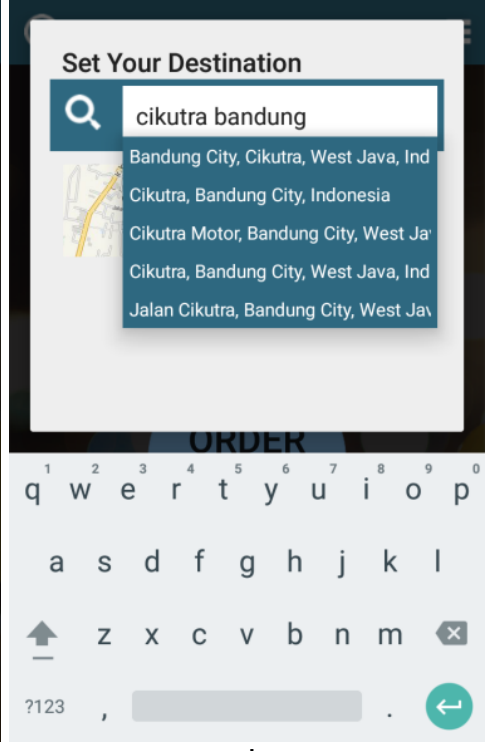

$\mathrm{b}$

Gambar 3 (a) (b). Tampilan Proses Pemesanan Taksi 
Gambar 3 (a) dan 3 (b) menunjukkan proses pemesanan taksi. Gambar 3 (b) adalah antarmuka pertanyaan system kepada pengguna apakah akan menentukan lokasi tujuan atau tidak. Lokasi tujuan digunakan untuk menghitung estimasi waktu perjalanan dan biaya. Gambar 3 (b) adalah antarmuka proses memasukkan lokasi tujuan dengan cara menuliskan nama jalan atau nama tempat tujuan.

2. Antarmuka aktivitas proses pencarian taksi

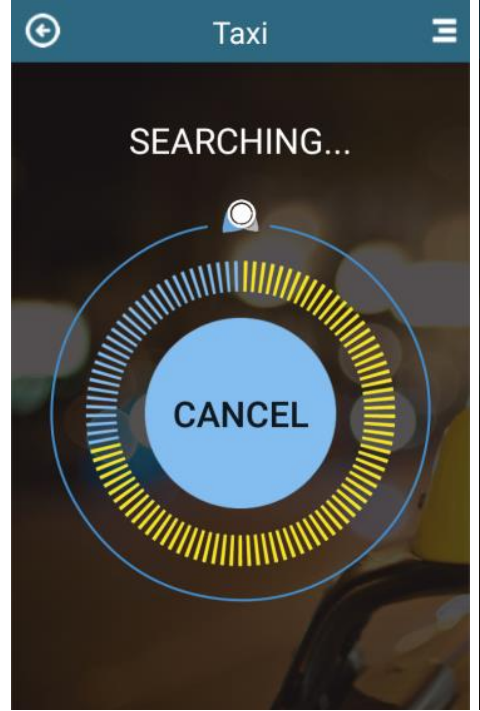

a

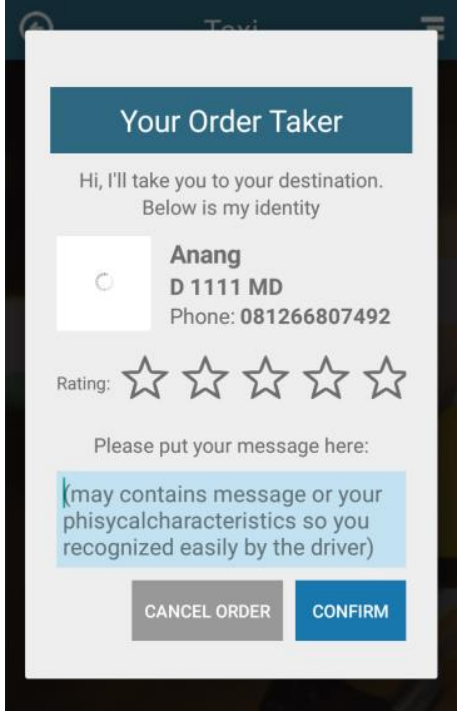

b

Gambar 4 (a) (b). Tampilan Proses Pencarian Taksi

Antarmuka proses pencarian taksi oleh sistem pada Gambar 4 (a) berisi countdown timer menggunakan animasi berbentuk lingkaran dengan tombol dengan teks cancel bagian tengahnya. Tombol cancel memungkinkan pengguna membatalkan pemesanan. Apabila ada taksi yang menerima pesanan maka tampil antarmuka pesanan diterima seperti ditunjukkan Gambar 4 (b).

3. Antarmuka aktivitas menilai taksi

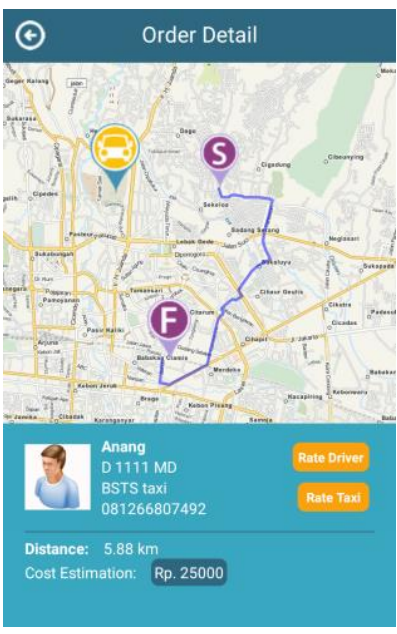

a

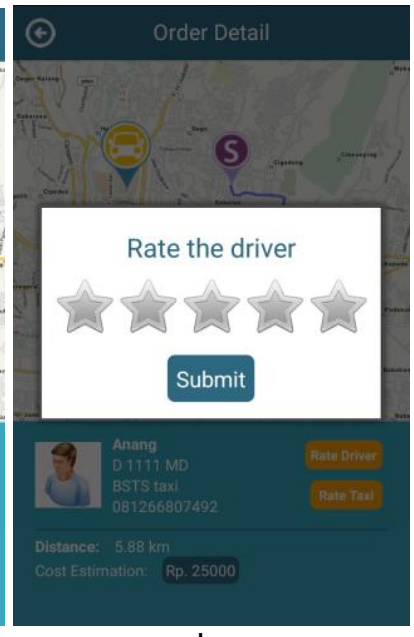

b

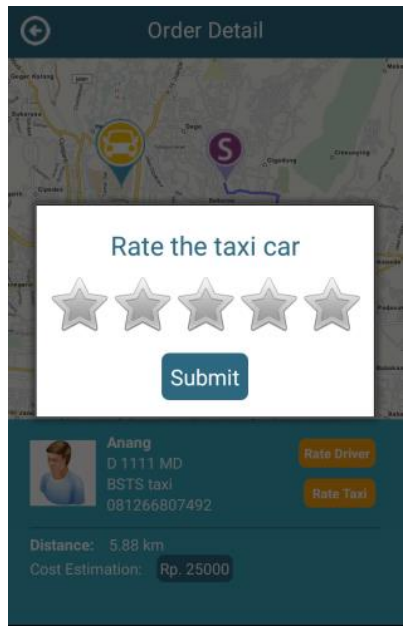

C

Gambar 5 (a) (b) (c). Tampilan Proses Penilaian Penumpang Terhadap Pengemudi dan Taksi 
Proses menilai pengemudi dan taksi dimulai dari halaman detail transaksi pesanan yang ditunjukkan pada Gambar 5 (a). Proses menilai taksi yang dirancang menggunakan skor 0 sampai dengan 5, dibuat dalam bentuk lima bintang yang ditunjukkan Gambar 5 (b) dan Gambar 5 (c). Pengguna dapat menekan bintang mana pun untuk memberikan nilai. Bintang paling kiri, nilainya 1 dan bintang paling kanan bernilai 5. Apabila pengguna menekan tombol submit tanpa menekan bintang mana pun, maka nilai yang diberikan adalah 0 .

4. Antarmuka aktivitas isi identitas pengemudi

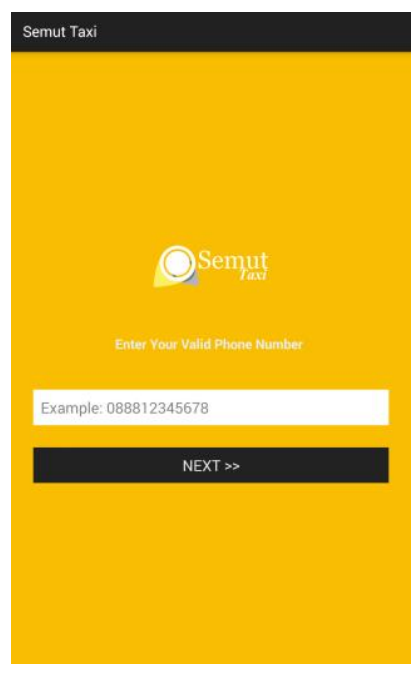

a

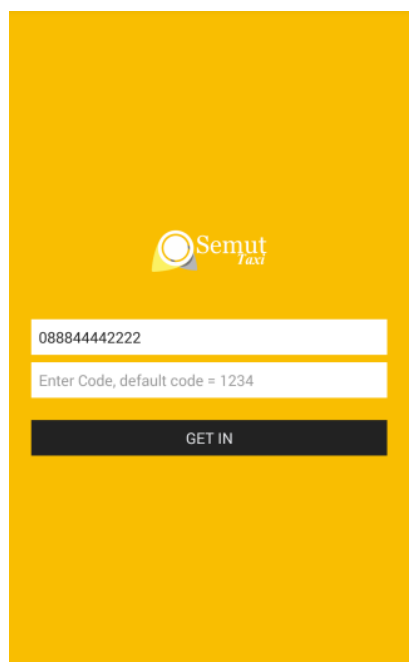

b

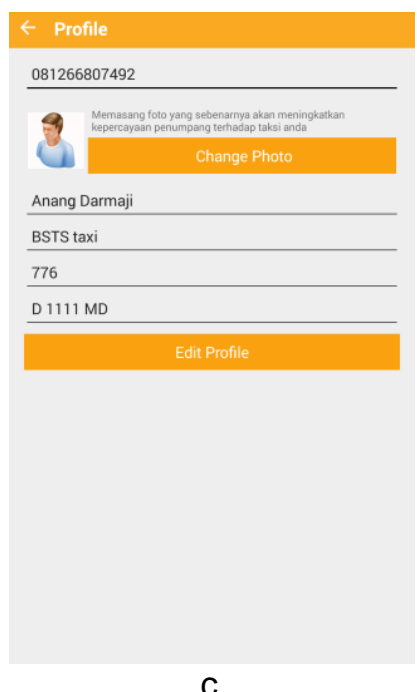

C

Gambar 6 (a) (b) (c). Tampilan Proses Isi Identitas Pengemudi Taksi

Mengisi identitas pengemudi taksi dimulai dari proses login menggunakan nomor telepon. Gambar 6 (a) dan Gambar 6 (b) menunjukkan tampilan untuk proses login pengemudi. Pengemudi memasukkan nomor telepon dan selanjutnya memasukkan kode verifikasi yang didapatkan dari pesan singkat yang dikirim oleh sistem. Setelah berhasil login, pengemudi dapat mengisi identitas diri dan taksinya yang ditunjukkan Gambar 6 (c).

5. Antarmuka aktivitas standby aplikasi Semut Taxi

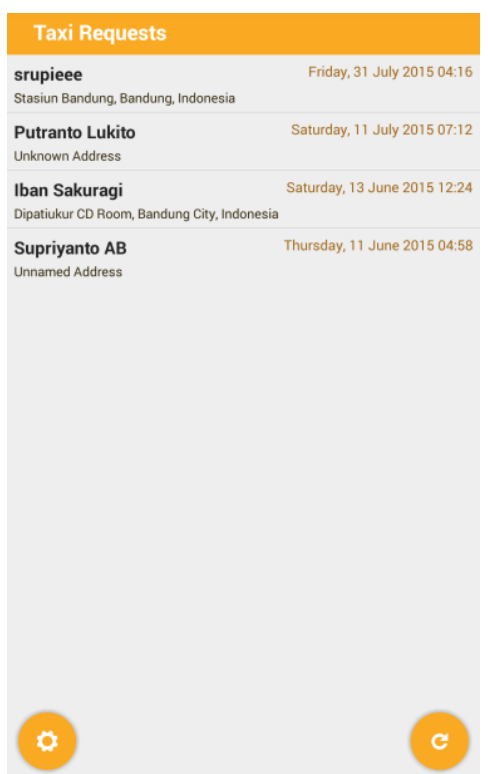

Gambar 7. Tampilan Standby Semut Taxi

KINETIK Vol. 2, No. 1, Februari 2017: 43-52 
Gambar 7 menunjukkan tampilan standby Semut Taxi cukup sederhana yang berisi daftar permintaan pesanan terbaru dari calon penumpang. Daftar permintaan pesanan akan berubah secara berkala. Hal ini dipengaruhi oleh permintaan pesanan tersebut telah diterima oleh taksi lain atau calon penumpang membatalkan permintaannya.

6. Antarmuka aktivitas menerima pesanan

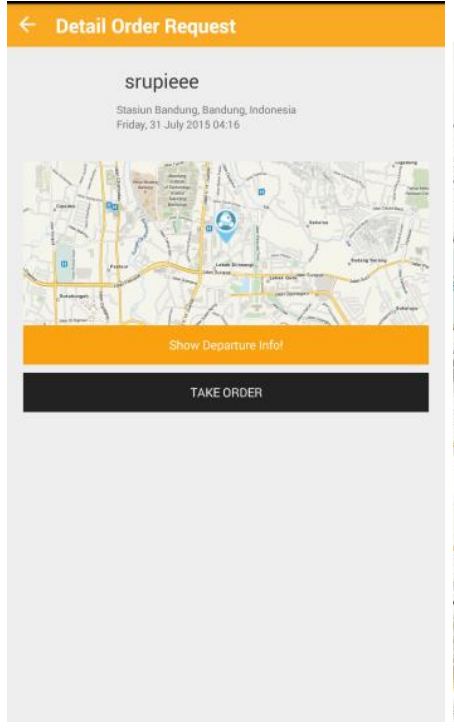

a

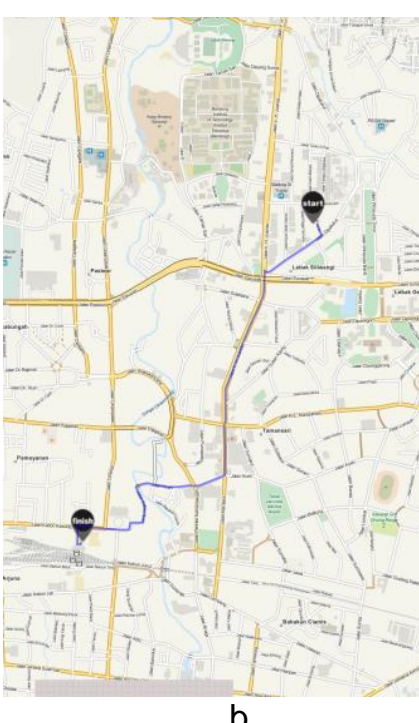

$b$

Gambar 8 (a) (b). Tampilan Detail Informasi Permintaan Pesanan Taksi

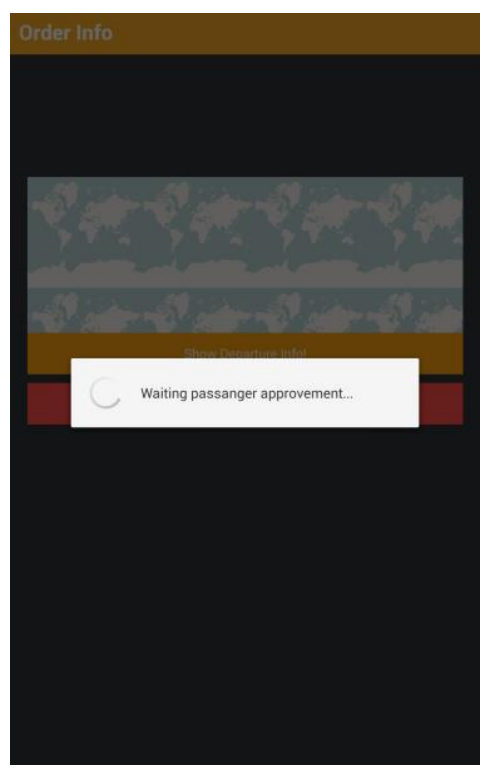

a

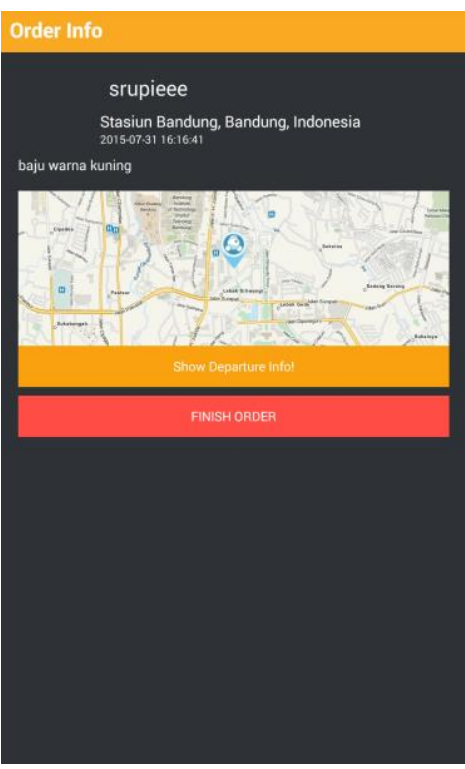

b

Gambar 9 (a) (b). Tampilan Proses Konfirmasi Transaksi Pesanan Taksi

Tampilan menerima pesanan dimulai dari Gambar 8 (a) dan 8 (b), pengemudi dapat melihat detail permintaan pesanan taksi. Informasi yang didapatkan pengemudi adalah nama calon penumpang dan lokasi tujuan yang dilengkapi dengan tampilan peta. Pengemudi harus menunggu konfirmasi dari calon penumpang seperti ditunjukkan Gambar 9 (a). Gambar 9 (b) menunjukkan transaksi sudah berjalan dan pengemudi menekan tombol finish order ketika transaksi sudah selesai atau penumpang sudah turun. 


\subsection{Pengujian}

Pengujian desain interaksi pada gamifikasi pemesanan taksi online baru dilakukan dalam bentuk pengujian fungsional. Pengujian fungsional menguji fungsi setiap tampilan dan fitur berdasarkan urutan prosesnya. Sedangkan pengujian untuk menguji capaian target desain interaksi yang dibuat belum dilakukan.

Suatu pengujian sistem pemesanan taksi online pada Semut App melibatkan 40 responden tahun 2015 [2], didapatkan hasil sebagai berikut:

1. Sebanyak $63 \%$ responden sangat setuju bahwa pemesanan taksi online pada Semut App lebih cepat, mudah, efektif, dan efisien.

2. Sebanyak $63 \%$ responden menyatakan sangat setuju bahwa pemesanan taksi online dikemas dengan cara yang menarik.

3. Sebanyak $50 \%$ responden sangat setuju dan $45 \%$ responden setuju bahwa penerapan gamifikasi dapat memberikan motivasi lebih kepada responden untuk menggunakan layanan taksi.

\section{Kesimpulan}

Berdasarkan hasil pengujian tersebut, dapat sedikit ditarik kesimpulan bahwa desain interaksi yang telah dibuat dapat mencapai target dan tujuannya. Gamifikasi dalam pemesanan taksi online dapat membuat responden termotivasi dan menginginkan selalu menggunakan aplikasi Semut App.

Namun, pengujian tersebut belum dapat membuktikan bahwa desain interaksi yang dibuat berhasil mencapai target dan tujuan. Maka perlu dilakukan pengujian yang dapat mencatat setiap aktivitas pemesanan taksi baik dari sisi penumpang maupun pengemudi taksi. Sehingga dapat diukur lebih baik lagi, apakah target/tujuan pembuatan desain interaksi dalam gamifikasi pemesanan taksi online sudah tercapai atau belum.

\section{Referensi}

[1] T. Rosenbloom and A. Shahar. "Differences Between Taxi and Nonprofessional Male Drivers in Attitudes Towards Traffic-violation Penalties." Transp. Res. Part F Traffic Psychol. Behav. Vol. 10.5, (2007): 428-435.

[2] Supriyanto, H. Hindersah, and A. S. Prihatmanto. "Designing Gamification for Taxi Booking System (Case study: Bandung Smart Transportation System)." in 2015 4th International Conference on Interactive Digital Media (ICIDM), (2015): 1-6.

[3] S. Deterding and D. Dixon, "Gamification: Using Game Design Elements in Non-Gaming Contexts." in CHI 2011: Conference on Human Factors in Computing Systems, (2011): 5-8.

[4] R. Harle, Activity-Centered Design: An Ecological Approach to Designing Smart Tools and Usable Systems by Geri Gay and Helene Hembrooke . MIT Press , Cambridge, MA, U.S.A., 2004. 144 pp., illus. Trade. ISBN: 0-262-07248-3. Vol. 38.3. 2005.

[5] K. Werbach and D. Hunter. "For The Win: How Game Thinking Can Revolutionize Your Business." Philadelphia: Wharton Digital Press, 2012. 